\title{
Formation of Artificially-Layered High-Temperature Superconductors Using Pulsed-Laser Deposition
}

\author{
D. P. Norton, B. C. Chakoumakos, and J. D. Budai
}

March 1995

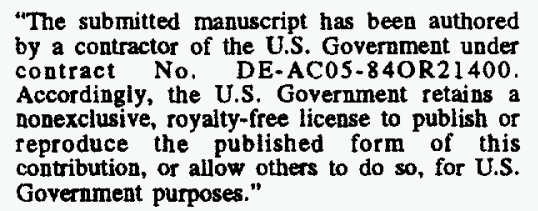

Prepared by

Solid State Division

Oak Ridge National Laboratory P.O. Box 2008

Oak Ridge, Tennessee 37831-6056

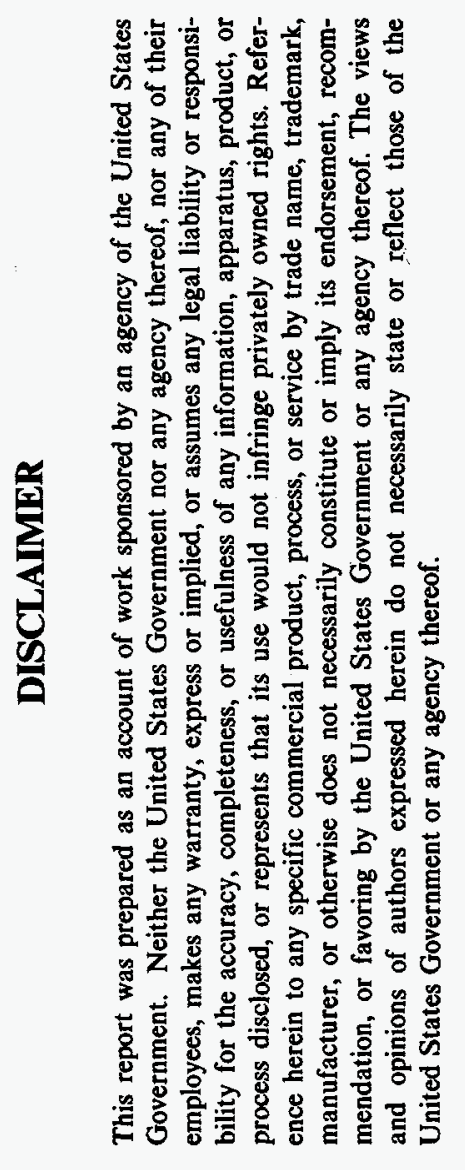
managed by
MARTIN MARIETTA ENERGY SYSTEMS, INC. for the
U.S. DEPARTMENT OF ENERGY under contract DE-AC05-84OR21400




\section{DISCLAIMER}

Portions of this document may be illegible in electronic image products. Images are produced from the best available original document. 


\section{Summary}

Formation of Artificially-Layered High-Temperature Superconductors Using Pulsed-Laser Deposition

D. P. Norton, B. C. Chakoumakos, and J. D. Budai

Oak Ridge National Laboratory

P. O. Box 2008

Oak Ridge, TN 37831-6056

USA

Pulsed-laser deposition has been used to synthesize artificially-layered hightemperature superconductors. Novel thin-film $\mathrm{SrCuO}_{2} / \mathrm{BaCuO}_{2}$ superlattices have been synthesized which superconduct at temperatures as high as $70 \mathrm{~K}$. These results demonstrate that pulsed-laser deposition and epitaxial stabilization can be effectively used to engineer artificially-layered thin-film materials. 


\title{
Formation of Artificially-Layered High-Temperature Superconductors Using Pulsed-Laser Deposition
}

\author{
D. P. Norton, B. C. Chakoumakos, and J. D. Budai \\ Oak Ridge National Laboratory
}

P. O. Box 2008

Oak Ridge, TN 37831-6056

USA

The layered structure of the copper oxide superconductors opens the possibility of forming novel materials by carefully controlling the epitaxial growth of sub-units of the crystal structures. Thin-film growth methods, such as pulsed-laser deposition (PLD), offer unique opportunities for the atomic engineering of new high-temperature superconducting (HTSc) materials through the ability to form artificially layered crystal structures. Moreover, the surfaces of single-crystal substrates provide an "atomic template" that can be used to stabilize epitaxial films in metastable crystal structures. A necessary milestone in the effort to form new artificially-layered HTSc structures is to control the growth of "infinite layer" $(\mathrm{Ca}, \mathrm{Sr}) \mathrm{CuO}_{2}$ films at the unit-cell level $(\sim 3.4 \AA)$. The infinite-layer structure can be viewed as a fundamental building unit of all of the HTSc cuprates.

We have recently demonstrated that unit-cell control of $(\mathrm{Sr}, \mathrm{Ca}) \mathrm{CuO}_{2}$ growth can be achieved using pulsed-laser deposition over an oxygen pressure regime in which in situ surface analysis techniques, such as reflection high-energy electron diffraction, are not possible. 1 We have successfully grown $\mathrm{SrCuO}_{2} /(\mathrm{Sr}, \mathrm{Ca}) \mathrm{CuO}_{2}$ superlattice structures utilizing a conventional PLD multi-target system operating at an oxygen pressure of 200 mTorr. X-ray diffraction peaks attributed to the superlattice structures are observed, even for $\mathrm{SrCuO}_{2} /(\mathrm{Sr}, \mathrm{Ca}) \mathrm{CuO}_{2}$ superlattice structures with $\mathrm{SrCuO}_{2}$ and $(\mathrm{Sr}, \mathrm{Ca}) \mathrm{CuO}_{2}$ layer thicknesses of a single unit cell $(\sim 3.4 \AA)$. The $\mathrm{x}$-ray diffraction data also reveal finite-thickness oscillations in the $x$-ray intensity, which is indicative of films with extremely flat surfaces. The growth of superlattice structures by PLD is made possible, in large part, by this surface flatness.

Utilizing this capability, we have also synthesized a new series of artificially-layered HTSc compounds, grown as $\mathrm{SrCuO}_{2} / \mathrm{BaCuO}_{2}$ crystalline 
superlattice structures. ${ }^{2}$ While previous efforts to grow artificially-layered cuprate structures have been restricted to sophisticated MBE-like apparatus using in situ surface analysis techniques, we have formed these materials simply using pulsed-laser deposition. By sequentially depositing from $\mathrm{BaCuO}_{2}$ and $\mathrm{SrCuO}_{2}$ ablation targets in a PLD system, artificially-layered crystalline materials were constructed in which the layering sequence was controlled on nearly the atomic-layer scale. The $\mathrm{SrCuO}_{2}$ and $\mathrm{BaCuO}_{2}$ layers are epitaxially stabilized in the infinite layer structure, and form the building blocks for the compounds. Note that $\mathrm{SrCuO}_{2}$ in the infinite layer structure is an insulator, while $\mathrm{BaCuO}_{2}$ normally does not form the infinite layer structure, even by high-pressure synthesis techniques. Utilizing this approach, we have synthesized a new HTSc series, $\mathrm{Ba}_{\mathrm{m}} \mathrm{Sr}_{n-1} \mathrm{Cu}_{n+1} \mathrm{O}_{2 n+\mathrm{m}+\delta}$ with $T_{c}$ (onset) and $T_{c}$ (resistance, $R=0$ ) as high as $70 \mathrm{~K}$ and $50 \mathrm{~K}$, respectively. These results represent not only the synthesis of new structural families of superconductors, but also demonstrate that pulsed-laser deposition and epitaxial stabilization can be effectively used to engineer artificially-layered thin-film materials.

This work is supported by the Division of Materials Sciences, U.S. Department of Energy under contract DE-AC05-84OR21400 with Martin Marietta Energy Systems, Inc.

1. D. P. Norton, J. D. Budai, D. H. Lowndes, and B. C. Chakoumakos, "SrCuO $/(\mathrm{Sr}, \mathrm{Ca}) \mathrm{CuO}_{2}$ Superlattice Growth by Pulsed-Laser Deposition," Appl. Phys. Lett. 65, 2012 (1994).

2. D. P. Norton, B. C. Chakoumakos, J. D. Budai, D. H. Lowndes, B. C. Sales, J. R. Thompson, and D. K. Christen, "Superconductivity in $\mathrm{SrCuO}_{2}-\mathrm{BaCuO}_{2}$ Superlattices: Formation of Artificially Layered Superconducting Materials," Science 265, 2074 (1994). 